\title{
Impact of feed optimization and extension intervention on productive and reproductive performance in commercial dairy farms of urban areas in the eastern region of Ethiopia
}

\author{
Ewonetu Kebede Senbeta $^{1}$, Negassi Ameha Zeleke ${ }^{2}$ and Gemechu Taffa Dingidie ${ }^{3}$ \\ Received: 07 February 2021 / Accepted: 09 March 2021 / Published online: 27 July 2021 \\ (c) Indian Dairy Association (India) 2021
}

\begin{abstract}
This study aimed at assessing the husbandry practices and evaluating the impact of feed optimization on productive performances and reproductive disorders of dairy cows. The study was conducted on purposefully selected 76 and 16 dairy farms for pre-and post-intervention study, respectively, from Harar and Dire Dawa cities. Data were collected by semi-structured questionnaires and focused group discussion starting from October 2018 to September 2020. Commonly used feeds were standardized to the cows' requirement. Milk yield was recorded every day for four consecutive months while milk composition was evaluated every month. Data analysis was done by SPSS, one-way ANOVA, and t-Test. The pre-intervention results showed that farmers from the small, medium, and largescale farms fed cows on low concentrate quantity of 3.76, 4.61, and $5.84 \mathrm{Kg} /$ day, respectively. The quantity of concentrate supplementation per cow per day was significantly different $(\mathrm{p}<0.0001)$ among farm-scales. Cows maintained under different farm-scales produced low milk yields (9.57-13.07 litter). Cows from large-scale farms significantly produced milk with lower fat $(\mathrm{P}<0.0006)$ whereas small-scale farms produced milk with lower protein and milk urea $(\mathrm{P}<0.0001)$. All milking cows maintained in small, medium, and large farm-scales were highly affected by anestrus $(44.45 \%)$, placenta retention $(35.19 \%)$, and repeat breeding $(20.37 \%)$. The technical intervention of feed optimization boosted daily milk yield from 17.64 to $27.44 \%$, enhanced most milk components except fat and milk urea, and reduced the
\end{abstract}

\footnotetext{
1, 2 \&3 Haramaya University, School of Animal and Range Science, P. O. Box 138, Dire Dawa, Ethiopia
}

Ewonetu Kebede Senbeta $(\square)$

Haramaya University, School of Animal and Range Science, P. O. Box 138, Dire Dawa, Ethiopia

Email: ewonetu2011@gmail.com, ORCID: 0000-0002-3303-2194 incidence of anestrus $(11.11 \%)$, retention of the placenta (5.56$11.11 \%)$, repeat breeding (11.11-22.22), dystocia (5.56-11.11\%) and prolapse (5.56\%). Finally, this study concluded that regular technical advice and feed optimization improved milk production and reduced reproductive disorders of dairy farmers in all farm categories.

Keywords: Cows, Farm-scales, Intervention, Milk production, Reproductive disorders

\section{Introduction}

In Ethiopia, market-oriented dairy farming primarily contributes to the supply of milk and milk products in urban centers (Mekonnen et al. 2006). The Ethiopian government has recently given considerable attention to the need to increase milk production (Belay and Geert, 2016). For this purpose, the government consistently introduced improved breeds and semen to dairy farmers. These genetically improved breeds are mostly kept in the urban area of the country due to the adequate availability of feeds and veterinary services (Azage et al.2013). The urban commercial dairy producers would rely almost exclusively on artificial insemination for better semen and pay for the more expensive imported genetics and breeding supplies. Despite this, cows reared under different commercial farm-scales were producing less daily milk, 5-15 litres (Azage et al. 2000), and total milk production per lactation, 3208.56 litres (Dessalegn et al. 2016) which is by far lower than 5807 litres reported in other African countries (Naceur et al. 2012). The lower milk production under commercial farms can be attributed to many constraints, but the most important factors repeatedly raised are the animal's genetic potential and feed (Belay and Geert, 2016). However, so many dairy farmers claim that poor breed quality has much more adverse effect on milk production than inadequate feeding. Conversely, others (Van Marle-Köster and Webb, 2014) suggested that the improvement of the genetic potential of dairy cattle increases milk yield if feed management skills are acquired and animal health care services are accessed by dairy farmers. For this reason, this research was done to examine the effect of feed optimization along with training, advice, and proper followup action on milk production and composition and reproductive disorders of dairy farms with different husbandry practices and 
farm-scales. Therefore, the objectives of this study were to assess the husbandry practices and standardize feed to the requirements of peak stage lactating cows and evaluate its impact on milk yield, milk composition, and reproductive disorders of lactating cows maintained under different husbandry and farm sizes.

\section{Materials and Methods}

\section{Baseline and post-intervention study}

The study was conducted in the eastern region of Ethiopia in and around Dire Dawa and Harar cities. Based on their willingness to engage in training and share experience at Haramaya University dairy farm, 23 small-scales (owned milking cows $\leq 10 ; 10$ from Dire Dawa and 13 from Harar), 34 medium-scales (owned milking cows between 11 to 20; 18 from Dire Dawa and 16 from Harar), and 19 large-scales (owned milking cows $>20$; 12 from Dire Dawa and 7 from Harar) were purposefully selected. Survey data on husbandry practices were collected using semi-structured questionnaires, detailed assessment of farm notebook records, and focused group discussion (FGD). A total of 152 Holstein Friesian with Zebu crossbred cows (HFCC) within 3-5 parity, two from each farm were deliberately selected based on their population and assessed for their reproductive disorders, milk yield, and composition. A format was distributed to each farm to record data on milk and reproductive disorders by the farm head and was collected monthly. Reproductive disorders such as retained placenta, dystocia, anoestrus, repeat breeder, and prolapse that occurred to each cow in each farm were recorded based on existing definition (Adane et al. 2017). All identified dairy farm owners and/or their representatives were invited and trained on dairy production and management and shared practical skills at the Haramaya University dairy farm. Then, each farm was visited once monthly for four consecutive months during the pre-intervention to crosscheck the actual and adapted practices regardless of their farm-scales. However, only 16 farm owners (8 medium-scale; 4 from Dire Dawa and 4 from Harar, and 8 large-scales; 4 from Dire Dawa and 4 from Harar) who fulfilled all the required quantity and necessary feed ingredients used in ration formulation were purposefully considered in the postintervention assessment. The post-intervention assessment was done on 48 HFCC (3 milking cows from each farm) which were purposefully selected based on their similar pregnant stage and parity then monitored starting from three weeks before calving to 120 days post-calving. The advice was given to all farm attendants to feed their cows separately twice a day at a rate of $0.5 \mathrm{~kg}$ per $1 \mathrm{~kg}$ of milk (Pandey and Voskuil, 2011), provide water and roughage feeding ad libitum, and to measure daily feed and milk produced.

\section{Nutritional analysis and ration formulation}

Milk sample was taken every month from each cow $(100 \mathrm{ml})$ and pooled for cows in the same farm and separately analysed in duplicate for composition in the morning and afternoon by MilkoScan $^{\mathrm{TM}}$ FT1. Commonly provided feed was collected from each farm and samples of the same feed type were pooled, thoroughly mixed, sub-sampled (500 g) and analysed (AOAC, 2000) for their nutritional content. Accordingly, a ration was formulated from ground maize, wheat bran, wheat short, soybean meal, peanut meal, salt, ruminant premix, and di-calcium phosphate by feedWin at a proportion of $29,31.2,18,5,15,0.8,0.5$, and $0.5 \%$, respectively, so that it contains 18.02 crude protein and $61.2 \%$ TDN. Thereafter, the format that indicated this feed proportion was printed and distributed to all farms considered in the post-intervention so that they could make their ration at their farm with the same ingredients and amounts.

\section{Statistical analysis and model}

All the survey data were analysed for percentage and means by SPSS version 20. The concentrate supplementation, milk yield, and composition data were subjected to one-way ANOVA of SAS version 9.4 while the comparison data were analysed by tTest Paired for two samples for means to recognize the impact of the technical-intervention. The statistical model: $Y i j=\mu+F i+$ eij; where: $Y_{i j}$ is the $J^{\text {th }}$ observation of the $i^{\text {th }}$ farm-scale; $\mu$ is the population mean; $F_{j}$ is farm-scale (small, medium, and large); and $e_{i j}$ is the random residual effect. The existence of significant effect among farms was separated by Duncan's multiple range tests at $5 \%$ level of significance.

\section{Results and Discussion}

\section{Pre-intervention husbandry practices}

Across all the farm categories in the study area, Friesian crosses accounted for 82.8 percent and were the largest proportion of the herd maintained by farm owners due to higher milk productivity, but the majority of the farm owners did not know their exact crossbreed levels. Small size dairy farmers keep relatively many local cow breeds in their herd $(18.7 \%)$ due to the lower feed requirements and a higher concentration of milk solids. Besides, small-scale dairy farming is their ancillary occupation $(88.7 \%)$ unlike the medium-scale (91.6\%) and large-scale (100\%) which are running their farm as the main business.

Natural mating was the most $(67.5 \%)$ practised breeding method in all the study farms whereas AI services were utilized mostly $(31.4 \%)$ by small-scale farms with a desire to improve the genetic potential of their animals by superior bull's semen. The majority (95.60) of dairy farmers did not keep proper records relating to the date of birth, breeding, vaccinations, past health problems, treatment given, and daily milk yield for individual cows. Almost all farms $(95.2 \%)$ were managed by owners who did not possess the relevant professional training and this was the cause for a large number of farms being managed in traditional ways with little or no improved management practices. This is in line with 
the result indicated by Ponnusamy et al. (2019) and Patel et al. (2020).

\section{Concentrate feeding practices and levels}

A majority of dairy farmers fed their milking cows on concentrate at different proportions across all the farm categories (Table 1). The quantity of concentrate supplementation per cow per day was significantly different $(\mathrm{p}<0.0001)$ among farm-scales, whereas the quantity of concentrate supplementation per liter of milk was not. The amounts of concentrate used in large-scale farms were higher than in other farm sizes. This indicates that they give more care to their cows as they have comparative advantages in milk production which is consistent with the study reported by Gelila (2017). However, quantities used in all farm sizes were lower than the recommended, 6.5-10.5 kg/day (Kavanagh, 2015). The compound concentrate feeding based on milk yield was also below the recommended, $0.5 \mathrm{~kg} / \mathrm{kg}$ of milk, which is the point of biological and economic optima (Pandey and Voskuil, 2011).

\section{Milk yield and composition}

Mean daily milk yield at peak lactation stage under different farmscales was significantly different $(\mathrm{p}<0.0001)$ (Table 1$)$. The overall recorded daily milk yield per cow in all the farms in the study was lower than the expected level (20 liters) reported in an earlier study for crossbred cows in Ethiopia (Azage et al. 2000). Cows from the small-scale farms were produced lower yields than cows from the medium and large farm-scales and this is consistent with earlier study reports (Gelila, 2017). This could be due to lower concentrate level utilization. Cows from the large-scale farms were significantly produced milk with lower in milk fat $(\mathrm{P}<0.0006)$ than cows from the other farm-scales, whereas cows from the small-scale farms were produced milk with lower protein and milk urea (MU) $(\mathrm{P}<0.0001)$ than cows from the other farm scales (Table 1). The fat and solid not fat components from cows of all farms were higher than the lower limit $3.5 \%$ and $8.5 \%$, respectively.

\section{Major reproductive problems}

Anestrus, retention of placenta, and dystocia were prevalent among the reproductive disorders (Table 2) and this corresponded to results reported earlier (Khan et al. 2016; Patel et al, 2020). Cows maintained under small-scale farms were more affected by anestrus, retention of the placenta, and repeat breeding. This might be due to the lower quantity of concentrate supplementation (Table 1) and the intensive use of AI. The overall prevalence of repeat breeding and anestrus in this study was within the range of 5-30\% (Patel et al, 2020; Gupta and Deopurkar, 2005; Hunduma, 2013) and 10-40\% reported by Zdunczyk et al. (2002), respectively. The incidence of placenta retention in this study was higher than $18.3 \%$ which was reported by Degefa et

Table 1 Pre-intervention concentrate supplementation and milk yield and composition ( $\mathrm{n}=76)$

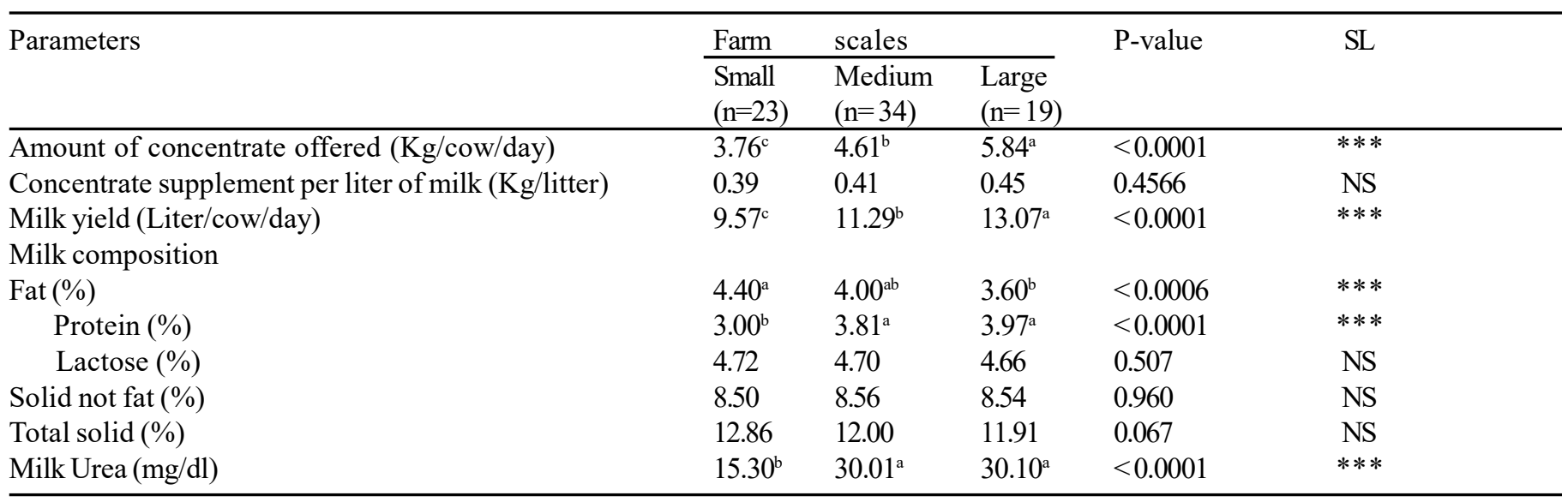

$\mathrm{a}, \mathrm{b}, \mathrm{c}$ - Different superscripts in a row are significantly different at $\mathrm{P}<0.05$.NS $=$ Non-significant; $\mathrm{SL}=\mathrm{Significant}$ level

Table 2 Major reproductive disorders assessed during pre-intervention study $(\mathrm{n}=76)$

\begin{tabular}{llllc}
\hline Reproductive disorders & Farm Scales & $(\%)$ & Overall mean \\
& Small $(\mathrm{n}=23)$ & Medium $(\mathrm{n}=34)$ & Large $(\mathrm{n}=19)$ & $76)$ \\
\hline Anestrus & 88.89 & 27.78 & 16.67 & 44.45 \\
Retention of placenta & 77.78 & 16.67 & 11.11 & 35.19 \\
Repeat breeding & 27.78 & 11.11 & 22.22 & 20.37 \\
Dystocia & 0.0 & 5.56 & 11.11 & 5.56 \\
Prolapse & 0.0 & 0.0 & 5.56 & 1.85 \\
\hline
\end{tabular}

$\mathrm{n}=$ number of sample farms 
Table 3 Least mean squares comparison of milk yield and composition for pre- and post-intervention study

\begin{tabular}{|c|c|c|c|c|c|c|}
\hline Parameters & Farm Scale & Pre-In(n=76) & Post-In(n=16) & P-value & $\mathrm{SL}$ & ${ }^{\Delta}$ Change $(\%)$ \\
\hline \multirow[t]{2}{*}{$\overline{\text { Milk yield }(\mathrm{L})}$} & Medium & $11.29^{b}$ & $15.56^{\mathrm{a}}$ & $<0.0001$ & $* * *$ & $4.27(27.44 \%)$ \\
\hline & Large & $13.07^{\mathrm{b}}$ & $15.87^{\mathrm{a}}$ & 0.0007 & $* * *$ & $2.80(17.64 \%)$ \\
\hline \multicolumn{7}{|c|}{ Milk composition $(\%)$} \\
\hline \multirow[t]{2}{*}{ Fat } & Medium & $4.00^{\mathrm{a}}$ & $3.64^{\mathrm{b}}$ & 0.004 & $* *$ & $-0.36(9.89 \%)$ \\
\hline & Large & $3.60^{\mathrm{a}}$ & $3.58^{\mathrm{a}}$ & 0.920 & NS & $-0.02(0.56 \%)$ \\
\hline \multirow[t]{2}{*}{ Protein } & Medium & $3.81^{\mathrm{a}}$ & $3.93^{\mathrm{a}}$ & 0.060 & NS & $0.12(3.05 \%)$ \\
\hline & Large & $3.97^{\mathrm{a}}$ & $3.98^{\mathrm{a}}$ & 0.920 & NS & $0.01(0.25 \%)$ \\
\hline \multirow[t]{2}{*}{ Lactose } & Medium & $4.70^{\mathrm{a}}$ & $4.73^{\mathrm{a}}$ & 0.447 & NS & $0.03(0.63 \%)$ \\
\hline & Large & $4.66^{\mathrm{a}}$ & $4.69^{\mathrm{a}}$ & 0.502 & NS & $0.03(0.64 \%)$ \\
\hline \multirow[t]{2}{*}{ Solid not fat (\%) } & Medium & $8.56^{\mathrm{b}}$ & $9.30^{\mathrm{a}}$ & 0.024 & $*$ & $0.73(7.85 \%)$ \\
\hline & Large & $8.54^{\mathrm{b}}$ & $10.10^{\mathrm{a}}$ & $<0.0001$ & $* * *$ & $1.56(15.45 \%)$ \\
\hline \multirow[t]{2}{*}{ Total solid (\%) } & Medium & $12.00^{\mathrm{b}}$ & $13.40^{\mathrm{a}}$ & 0.007 & $*$ & $1.4(10.45 \%)$ \\
\hline & Large & $11.91^{\mathrm{b}}$ & $12.90^{\mathrm{a}}$ & 0.002 & $*$ & $0.9(6.98 \%)$ \\
\hline \multirow{2}{*}{$\begin{array}{l}\text { Milk Urea } \\
(\mathrm{mg} / \mathrm{dl})\end{array}$} & Medium & $30.01^{\mathrm{a}}$ & $20.70^{\mathrm{b}}$ & $<0.0001$ & $* * *$ & $-9.31(44.96 \%)$ \\
\hline & Large & $30.10^{\mathrm{a}}$ & $22.20^{\mathrm{b}}$ & $<0.0001$ & $* * *$ & $-7.90(35.59 \%)$ \\
\hline
\end{tabular}

$\mathrm{n}=$ number of sample farms, Pre-In=Pre-intervention, Post-In=Post-intervention, $\mathrm{SL}=$ Significance level, NS=Non-significant $(\mathrm{p}>0.05)$, ${ }^{\Delta}=$ Performance change

Table 4 Influence of technical-intervention on some reproductive disorders

\begin{tabular}{lllll}
\hline Variables & Farm Scale & Pre-In(n=76) & Post-In(n=16) & ${ }^{\Delta}$ changes $(\%)$ \\
\hline Anestrus & Medium & 27.78 & 16.67 & 11.11 \\
& Large & 16.67 & 5.56 & 11.11 \\
Retention of & Medium & 16.67 & 11.11 & 5.56 \\
placenta & Large & 11.11 & 0.00 & 11.11 \\
Repeat breeding & Medium & 11.11 & 0.00 & -11.11 \\
& Large & 22.22 & 0.00 & -22.22 \\
Dystocia & Medium & 5.56 & 0.00 & -5.56 \\
& Large & 11.11 & 0.00 & -11.11 \\
Prolapse & Medium & 0.00 & 0.00 & 0.00 \\
& Large & 5.56 & 0.00 & -5.56 \\
\hline
\end{tabular}

$\mathrm{n}=$ number of sample farms, ${ }^{\Delta}=$ Performance change, Pre-In=pre intervention, post-In=post-intervention

al. (2011). The higher incidence of dystocia noted in the largesized farms might be due to the heavy grain feeding practices which are in line with the study reported by Grimard et al. (2006). These variations in the prevalence of reproductive health problems might be due to the differences in the husbandry system and genetic blood level of cows in each farm.

\section{Post-intervention husbandry practices}

The intervention practice through feed optimization significantly $(\mathrm{P}<0.0001)$ increased daily milk yield as compared to preintervention assessment (Table 3). This response indicates the higher potential of cows if they feed on the required quantity of balanced ration. In agreement with this study, an increased milk yield by $11.3 \%$ was reported after the feed was supplemented with $0.8 \mathrm{~kg}$ of concentrate per liter of milk produced (Fike et al. 2003). Besides, many scholars have illustrated an improved daily milk yield from 7 to over 24 liters (Lanyasunya et al. 2001) and 6.7-
7.6\% (Garg et al. 2014) after cows were fed a balanced ration. The technical feed intervention significantly $(\mathrm{P}<0.05)$ improved milk protein by 3.05 and $0.25 \%$, respectively, in medium and largesized farms, while it decreased fat by 9.89 and $0.56 \%$, in that order (Table 3). The decreased milk fat content in response to supplemented ration is consistent with the study finding reported by Garg et al. (2014). The decreased fat content can be attributed due to an increase in milk quantity in response to the higher concentrate supplementation which is in line with Ponnusmy et al. (2019).

An increased milk yield and milk components in this study could be due to an increased rumen microbial nitrogen synthesis in response to the feed optimization. Besides, the decreased MUN implied that cows were fed on a balanced ration with a suitable protein to energy ratio. The technical feed intervention also significantly $(\mathrm{P}<0.05)$ decreased the incidence of reproductive disorders as compared to pre-intervention (Table 4). The 
reduction of anestrus incidence is consistent with Alam and Sarder (2010). The more incidence of anestrus in the larger-sized farms might be due to the poor heat detection practices because of their large number of dairy animals. The reduction of placenta retention to zero percent in large-sized farms could be associated with improved feed management. The general variations in the occurrences of reproductive disorders among the studied farm scales were due to the differences in management and genetic blood level of cows kept in each farm. These results are in agreement with previous findings of Tesfaye and Shamble (2013), who reported the variation in the prevalence of major productive disorders in the dairy cows due to the differences in management and breed of the animals as well as environmental factors. Therefore, more extension efforts are required to educate the farmers on optimum feeding protocols as well as proper reproductive management of dairy animals to realise higher milk productivity.

\section{Conclusions}

In the study area, the majority of dairy farmers were used feed which is below the point of biological and economic optima. This study revealed improved milk production and reduced reproductive disorders at the different levels of dairy farms through the involvement of professionals with regular technical advice and feed optimization. Therefore, efforts should be undertaken to educate the farmers on the balanced feeding of dairy animals for improved dairy production in the study area.

\section{Acknowledgments}

The authors are thankful to the Ethiopian Institute of Agricultural Research for the grant and office of vice-president for research affairs of Haramaya University for their financial facilitation.

\section{References}

Adane M, Kaidi R, Hanzen C, England GC (2017) Risk factors of clinical and subclinical endometritis in cattle: a review. Turk J Vet Anim Sci 41: 1-11

Alam MM, Sarder MJ (2010) Effects of nutrition on production and reproduction of dairy cows in Bangladesh. The Bangladesh Veterinarian 27: 8-17

AOAC (2000) Official Methods of Analysis. International, Arlington, Texas, USA

Azage T, Berhanu G, Dirk H, Berhanu B, Yoseph M (2013) Smallholder dairy production and marketing systems in Ethiopia: IPMS experiences and opportunities for market-oriented development. IPMS (Improving Productivity and Market Success) of Ethiopian Farmers Project Working Paper 31. Nairobi: ILRI

Azage T, Tsehay R, Alemu G, Hizkias H (2000) Milk recording and herd registration in Ethiopia. In Proceedings of the $8^{\text {th }}$ Annual Conference of the Ethiopian Society of Animal Production (ESAP), Addis Ababa 90-104

Belay D, Geert PJ (2016) Assessment of feed resources, feeding practices and coping strategies to feed scarcity by smallholder urban dairy producers in Jimma town, Ethiopia. Springerplus 5: 717
Degefa T, Asmamaw D, Reta D (2011) Brucellosis and some reproductive problems of indigenous Arsi cattle in selected Arsi Zone's of Oromia Regional State, Ethiopia. Glob Vet 7: 45-53

Dessalegn G, Berhan T, Gebreyohanes B (2016) Study of productive and reproductive performance of cross breed dairy cattle under smallholder's management system in Bishoftu and Akaki Towns. Int J Agric 6: 913-917

Fike JH, Staples CR, Sollenberger LE, Macoon B, Moore JE (2003) Pasture forages, supplementation rate, and stocking rate effects on dairy cow performance. J Dairy Sci 86: 1268-1281.

Garg MR, Sherasia PL, Phondba BT, Hossain SA (2014) Effect of feeding a balanced ration on milk production, microbial nitrogen supply and methane emissions in field animals. Anim Prod Sci 54: 1657-1661

Gelila AP (2017) Challenges and opportunities of milk production under different urban dairy farm sizes in Ethiopia. Glob J Dairy Farm Milk Prod 5:274-280

Grimard B, Freret S, Chevallier A, Pinto A, Ponsart C, Humblot P(2006) Genetic and environmental factors influencing first service conception rate and late embryonic/foetal mortality in low fertility dairy herds. Anim Reprod Sci 91:31-44. doi: 10.1016/ j.anireprosci.2005.03.003.

Jorritsma R, T Wensing, TAM Kruip, PL Vos and JPTM Noordhuizen (2003) Metabolic changes in early lactation and impaired reproductive performance in dairy cows. Vet Res 34: 11-26

Gupta AG, Deopurkar RL (2005) Microbial study of gynecological infection in cattle. Indian J Anim Repord 14:118-119

Hunduma D (2013) Major reproductive disorders of dairy cows in and around Asella town, Central Ethiopia. J Vet Med Anim Health 5: 113-117

Khan MH, Manoj K, Pramod S (2016) Reproductive disorders in dairy cattle under semi-intensive system of rearing in North-Eastern India. Vet World 9: 512-518

Lanyasunya TP, Mukisira EA, Lokwaleput IK, Siamba DN (2001) Factors limiting optimization of smallholder peri urban dairy herd production in Kenya. Livestock Community and Environment. In: Proceedings of the $10^{\text {th }}$ Conference of the Association of Institutions for Tropical Veterinary Medicine, Copenhagen, Denmark 27-36

Mekonnen HM, Asmamaw K, Courreau JF (2006) Husbandry practices and health in smallholder dairy farms near Addis Ababa, Ethiopia. Prev Vet Med 74: 99-107

Naceur M, Bouallegue M, Frouja S, Ressaissi Y, KaurBrar S, Ben Hamouda M (2012) Effects of environmental factors on milk yield, lactation length and dry period in tunisian holstein cows, milk production an up-to-date overview of animal nutrition, management and health. Available from: DOI: $10.5772 / 50803$

Pandey GS, Voskuil GCJ (2011) Manual on improved feeding of dairy cattle by smallholder farmers. Golden valley agricultural research trust Lusaka, Zambia, 50

Patel, D, Ponnusamy, K and Verma, AP Verma (2020) Reproductive efficiency of dairy animals in different dairy production systems under field conditions. Int J Livest Res 10: 89-96.

Ponnusamy, K, Chakravarty, R and Sohanvir Singh (2019). Extension interventions in coping of farmers against effect of climate change in dairy farming. Indian J Dairy Sci 72: 430-436

Tesfaye D, Shamble A (2013) Reproductive health problems of cows under different management systems in Kombolcha, Noetheast Ehiopia. Adv Biomed Res 7: 104-108

Van Marle-Köster E, Webb EC (2014) A Perspective on the impact of reproductive technologies on food production in Africa. Adv Exp Med Biol 752: 199-211

Zdunczyk S, Mwaanga ES, Malecki-Tepicht J, Baranski W, Janowski T (2002) Plasma progesterone levels and clinical findings in dairy cows with post-partum anoestrus. Bull Vet Inst Pulawy 46:79-86 